\title{
Top Management Support and Project Team for System/IT- Project Success
}

\author{
Assist Lecturer. Mustafa Othman Alsaigh ${ }^{1}$, Dr. Nor Hidayati Zakaria ${ }^{2}$ \\ 'Department of Business Administration College of Administrative and Finance Sciences / Cihan University / \\ Sulaimanyah \\ ${ }^{2}$ Department of IT Management Faculty of Computing/University Technology Malaysia
}

\begin{abstract}
Although business performance has long been theoretically hypothesized to be dependent on the level of underlying Information Technology capability, there is a lack of adequate empirical studies to support this claim. In this thesis the researcher discusses how significant top management support and project team towards the success of IT project/system. Significance of IT project/system is the backbone of the organization performance. Based on a real-life case study of developer systems, a model that depicts the level significance of top management support and project team towards information systems success was conducted. To achieve this objectives, quantitative survey method were conducted with 28 developers in CICT department in Universiti Teknologi Malaysia. Data obtained is used to measure the relationship between top management support and project team towards the success of IT project/system for the organization performance. Results show possibility in business performance due to support of top management and project team in accessing information systems success. Recommendations and guideline to avoid developer resistance in systems success are also presented. An equally important future direction is a psychological understanding of the developers' perspectives, attitude strength, attitude structure, and shift resistance to change.
\end{abstract}

Keywords: IT: Information Technology; IS: Information System; AVE: Average Variance Extracted; PLS: Partial Least Squares; SEM: Structural Equation Modeling.

\section{Introduction}

Organizations are investing heavily in information technology (IT) systems to effectively integrate and coordinating these activities as well as shape the way they conduct their business. Success systems (IT-Projects) have taking a central position of competition ability between enterprises and organizations. However the most crucial issue is implementing the IT-Projects system well, successful implementation is the first step that leads to achieve success systems [1]. The success of systems lies with usage, maintenance and intensification during the system's post-implementation and exploitation phase [39]. Many researchers have referred to the success of systems (IT-Projects) in successive organizations in gaining benefit of implementing IT-Projects.

During the growth of a competitive global environment, despite the benefits that can be achieved from successful systems (IT-Projects), there is already evidence of high failure risks in success systems (IT-Projects). Therefore, one of the major research issues in IT-Projects today is the study of success systems. There is considerable pressure on most organizations to make their operational, tactical, and strategic processes more efficient and effective an information system (IS) is a group of components which can increase competitiveness and gain better information for decision making. Therefore various organizations have chosen to apply this group of components to their associations [1]. Consequently, the organizations decide to implement IS in order to improve the effectiveness and efficiency of the organizations. Information systems have become a major function area of business administration [2].

The primary goal of system/IT project has been to improve and increase information flow within an organization [13]. This is achieved by understanding of departments and functions across a company onto a computer system that serves the needs of all of the different departments. The sharing of a common database eliminated duplication by keying the same information into different computer systems. Support top management and project team of information also minimizes the risk of errors and failure of the system (Koch et al, 2001). The rise in popularity of system/IT project evidence of continued IT projects implementation in both the public and private sectors makes it important for senior management to understand the concerns and advantages and risks involved, also project team must be understand all the functions and so on when implementing system/IT project.

\section{Theoretical Context}

We will begin by discussing two successful factors that affect systems/IT projects, four factors of ISImpact [11]. We will then examine the effectiveness of these factors towards systems/IT projects. The high percentage of system failures in the last few years calls for adequate implementation of system/IT project 
implementation model. Based on this high rate of system implementation failures, this paper seeks to analyze two factors of system success; 1) Top management support, 2) Project team associated with system/IT project and then seeks to understand how are critical to success of system/IT project and how much the contribution of top management support and project team on systems/IT Projects success.

\section{A. System Implementation}

System implementation efforts offer extraordinary challenges to information technology professionals and the organizations impacted by the implementations. A successful implementation can reap vast rewards in organizational strengths and efficiencies. A failure can drain an organization of people, funds and vitality. Consequently, many people have puzzled over the reasons for the successes and failures experienced with these implementations [7].

The purpose of System Implementation successful can be summarized as follows: making the new system available to a prepared set of users (the deployment), and positioning on-going support and Maintenance of the system within the Performing Organization (the transition). At a finer level of detail, deploying the system consists of executing all steps necessary to educate the Consumers on the use of the new system, placing the newly developed system into production, confirming that all data required at the start of operations is available and accurate, and validating that business functions that interact with the system are functioning properly. Transitioning the system support responsibilities involves changing from a system development to a system support and maintenance mode of operation, with ownership of the new system moving from the Project Team to the Performing Organization [14]. This phase consists of the following processes:

- Prepare for System Implementation, where all steps needed in advance of actually deploying the application are performed, including preparation of both the production environment and the Consumer communities.

- Deploy System, where the full deployment plan, initially developed during System Design and evolved throughout subsequent lifecycle phases, is executed and validated.

- Transition to Performing Organization, where responsibility for and ownership of the application are transitioned from the Project Team to the unit in the Performing Organization that will provide system support and maintenance.

\section{B. Characteristics of the Organization's System Success}

The characteristics of the system/IT projects are important to successful implementation. Organizations must be careful to compare the capabilities of the software package under consideration for adoption to the specific needs of the organization. Differences in these different systems products can have major effects on the successful implementation of the IT projects.

Since the characteristics of top management support, project team, and systems/IT projects success is discussed later in this paper. First of two characteristic was identified as a success factors in the reviewed. Organization size was identified by several researchers as a success factor for systems/IT projects implementation success. [21][9][34]. [21] used organization size as a control variable. This is usually done with a characteristic or independent variable with a significant effect on the dependent variable but not a variable of interest in the study under analysis.

\section{Top Management Support}

Top management support has been consistently identified as the most important and crucial success factor in system/IT projects. Define top management to provide the necessary resources and authority or power for project success. Top management support in system/IT project has two main facets: (1) providing leadership; and (2) providing the necessary resources [33]. To implement system/IT project successfully, management should monitor the implementation progress and provide clear direction of the project. They must be willing to allow for a mindset change by accepting that a lot of learning has to be done at all levels, including themselves. In this paper, [21] stated that one organization characteristic, top management support was instrumental in explaining IT project success implementation. Top management must take an active role in leading the system/IT project implementation. The success of an IT projects implementation completely depends on the strong, sustained commitment of top management. The commitment when transferred down through the organizational levels results in an overall organizational commitment [25].

Similarly, [33] stated that there must be a demonstrated strong commitment to successfully implementing the system by showing strong leadership from senior management, limiting the initial scope of the project, and working towards achieving an early success. Leadership support is essential to obtain buy-in from all levels of the organization, especially since IT projects, by their nature, generate such widespread organizational change. Top management support of information systems refers to the degree to which top management understands the importance of the IS function and the extent to which it is involved in IS activities. Management comprises the senior leadership of an organization, which includes the Chief executive officer, Chief information 
officer, Chief operating officer, and other senior-level business executives. Support from top management facilitates many of the operational and strategic IT management activities. These activities include negotiation, IS planning, project management, and similar tasks. [14] Identified 10 factors in project development and indicated the need for top management support at the project level. They indicated that the continuous involvement from top management is invaluable in resolving problems when crises and convicts arise in an uncertain environment, which are also indicative of an IS environment. In a study of key information management issues, managers were asked to rank the issues affecting IS success. Top management support was found to be the most significant attribute, with improved communication, goal alignment, competitive advantage, and IS strategic planning as the next four ranked attributes [27].

\section{Project Team}

IT project team work and composition is important throughout the IT implementation project. IT project involves all of the functional departments and demands the effort and cooperation of technical and business experts as well as end-users. IT project implementation team comprises of, functional personnel and management, IT personnel and management, top management, IT consultants, parent company employees, management consultants, hardware vendor. The IT project team should be balanced, or cross functional and comprise a mix of external consultants and internal staff so the internal staff can develop the necessary technical skills for design. According to survey, having competent members in the project team is the fourth most important success factor for IS implementation. Further, the members of the project team(s) must be empowered to make quick decisions [10]. Project Management involves the use of skills and knowledge in coordinating the scheduling and monitoring of defined activities to ensure that the stated objectives of implementation projects are achieved. The formal project implementation plan defines project activities, commits personnel to those activities, and promotes organizational support by organizing the implementation process [22].

\section{E. Issues with IS Success Models and Measurement}

Research assessing the success of Information Systems (IS) has been ongoing for nearly three decades [36] [38] [3]. However, the scope and approach of these IS success evaluation studies has varied and there is little consensus on the appropriate measures of IS success. This complicates comparisons of results across studies and impedes the establishment of a cumulative research tradition [29]. Though the development of IS success models [36] [32] has been an important contribution, construct validation issues and concerns have largely remained under-addressed until relatively recently. In particular, these studies have not carefully addressed the nature of these constructs as either formative or reflective. Recent work by [31] suggests that there is a significant threat of miss specifying and validating constructs as 'reflective' [28]. They encourage reflection on the validity of many mainstream constructs employed in IS research over the past 3 decades and critique the almost universal conceptualization and validation of these constructs as reflective. They are politic in not citing specific infractions but, rather, list a range of studies and provide examples of constructs that have been 'properly' specified as reflective or formative.

\section{F. Choice of IS Success Constructs}

The [36] IS success model is most widely cited and has been a valuable contribution to our understanding of IS success. They classified existing measures of success into six constructs - System-Quality, Information- Quality, Organizational-Impact, Individual-Impact, Satisfaction, and Use. They suggest that in order to develop a comprehensive measurement model and instrument for a particular context, the constructs and measures should be systematically selected considering contextual contingencies, such as organization size or structure, or the technology and the individual characteristics of the system.

\section{G. Success Model Completeness}

In order to fully account for potentially countervailing constructs and measures of success (e.g., high quality but poor cost-effectiveness), model completeness is essential. Following a review of alternative models from the literature, [23] highlights the subjectivity inherent in the selection of a single construct [as a proxy for overall success]. This suggests that where the aim is to gain a full, overarching view of success, it is critical that the complete set of success constructs be employed, not a selected subset. [12] Suggests that the employment of only one or a subset of the dimensions of success as a surrogate for overall success may be one of the reasons for mixed results reported in the literature regarding the antecedents of success. Review of the literature on [36] identified 149 studies of IS success measurement as depicted in Table 1.1. 
Table 1.1 Empirical Studies Delone and McLean (1992-2005)[35]

\begin{tabular}{|l|l|l|l|}
\hline Constructs & Number of Studies & $\%$ & Cumulative \\
\hline Systems-Quality & 88 & $59 \%$ & $59 \%$ \\
\hline Information-Quality & 26 & $17 \%$ & $77 \%$ \\
\hline Individual-Impact & 21 & $14 \%$ & $91 \%$ \\
\hline Organizational-Impact & 9 & $6 \%$ & $97 \%$ \\
\hline Satisfaction & 3 & $2 \%$ & $99 \%$ \\
\hline Use & 2 & $1 \%$ & $100 \%$ \\
\hline Total & 149 & $100 \%$ & \\
\hline
\end{tabular}

From Table 1.1 the researcher observes that approximately $60 \%$ of studies employing [35] construct use a single construct, with over $90 \%$ using 3 or less. This is not to suggest that any specific study employing less than the full set is flawed one would have to consider the specific intent of each study (in fact we do not advocate the full set). Rather, it is our contention that at least a portion of these studies has inappropriately and nonreflective employed a subset of the constructs as an overarching measure of success. In light of the aforementioned infrequent attention to rationale for choice of constructs and given our concern with potential implications of an incomplete measure of overall success, this is a concern for advancing IS impact measurement.

\section{H. The Conceptual Model}

The researchers argue that a holistic measure for evaluating an IS should consist of dimensions that together look both backward (impacts), and forward (quality). Figure 1.1 depicts the study 'IS-Impact' conceptual model wherein the researcher sees a nexus between Impacts to date and Quality. The researchers define the ISImpact of an Information System (IS) as "a measure at a point in time, of the stream of net benefits from the IS, to date and anticipated, as perceived by all key-user-groups". The IS-Impact Model is a holistic index representing the stream of net benefits; the 'impact' half measuring net benefits to date, while the 'quality' half, forms our" best" proxy measure of probable future impacts, with 'impacts' being the common denominator.

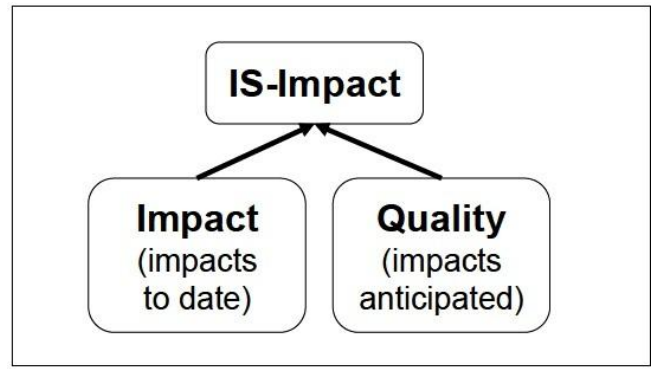

Figure 1.1 The Conceptual Model [11]

The proposed IS-Impact model has some basis in the [15] IS nomological net (IS-Net), wherein 'Quality' and 'Impact' have conceptual analogues, with 'Quality' being a measure of the IT-Artifact. Next, we reconcile [35] with the IS net by demonstrating the recursive nature of both. We then conceptually position the IS-Impact constructs within this reconciled and recursive nomological net, thereby facilitating discussion on the importance of the timing of measurement, and the appropriateness of cross-sectional measurement of the ISImpact dimensions. This discussion serves to both justify the IS-Impact view conceptually and operationally. Employing System-Quality and Information-Quality as measures of the IT Artifact (the Information System) is straightforward; as is Individual-Impact and Organizational-Impact as measures of overall Impact.

\section{K. Identifying a Pool of Measures and Dimensions}

Evaluation of candidate models and frameworks suggested the appropriateness as a starting set of measures, of those from the DeLone and McLean IS success model [36][35] [37]. [36] Identified six constructs: System-Quality, Information-Quality, Organizational-Impact, Individual-Impact, Satisfaction, and Use - within which they summarized commonality they observed across prior measures of information system success. It is noted that the System-Quality and Information-Quality constructs correspond logically with the Quality half of the study model in Figure 1.2; the Individual-Impact and Organizational-Impact constructs clearly corresponding with the Impact half of that model. Though predisposed to the inclusion of only these four constructs as dimensions in the a-priori model, in attention to model completeness, all six DeLone and McLean constructs were considered in subsequent citation analysis, as described following. 


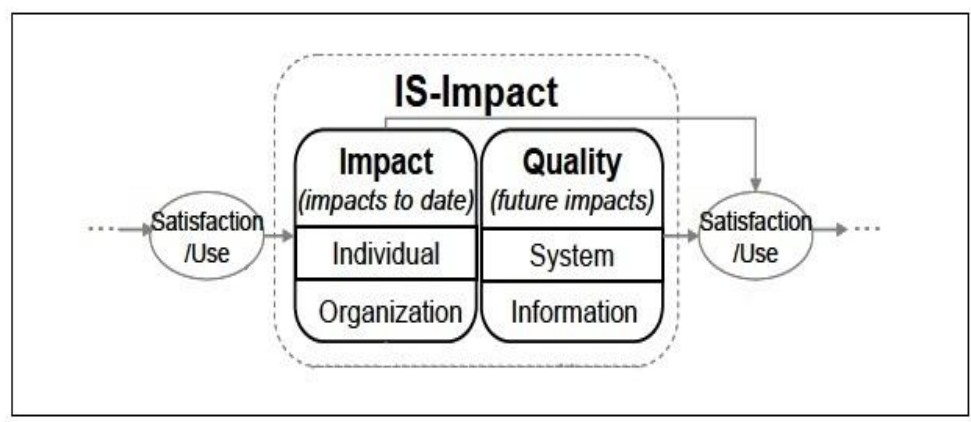

Figure 1.2 The IS-Impact Measurement Model [11]

\section{Individual Impact}

An interesting issue arose about the relevance of the individual impact outcomes. While interviewees across all the case organizations reported that the systems/IT projects simplified and speeded-up their individual work, several interviewees reported that this is not so "black and white." Since the systems offer far higher functionality, they also require more work to provide sufficient data. Moreover, the companies have started to place emphasis on data correctness and accuracy, and compared to the previous practice it can take more time to provide required information into the system. During systems/IT projects implementation in organizations there is a profound effect on the workplace and on the individuals at work. Often it is difficult to situate the project. Enlightened companies position the project from the outset as an enterprise project. A project team is created, composed of a Project Manager and a multidiscipline team comprised of Key Users and IT specialists.

\section{Information Quality}

Whether information quality is high or low must be assessed by the addressees of the information. From this perspective, various general criteria can be used to assess information quality in ecological statements. First, information is useless if it is not understood by the recipients. Second, it must be relevant to the particular environmental problems and to the users of ecological statements. However, even understandable and relevant information may be of limited value if it is not reliable, the methods of recording must be known and trustworthy, the presentation must be free from bias, uncertainties must be considered with prudence etc. Furthermore, the value of information is influenced by its comparability over time (consistency) and between companies. However, most cases of environmental reporting are characterized by an information asymmetry between the providers and the recipients of ecological statements. In general, the involved employees are better informed about the actual environmental impacts of a given production process than management or external stakeholders. In many cases the recipients of information know little about specific processes and therefore can hardly judge the quality of given information.

\section{N. System Quality}

The results showed that the case organizations reported a substantial number of IT project outcomes within the system and information quality dimensions, compared to the individual and organizational impact dimensions. This might be influenced by the lack of a strategic perspective on the system implementation in the studied the main reason for

Implementing system was to replace the legacy system. The previous systems were so unsatisfactory that their replacement was necessary for continuing the organizations operations. In previous systems were old solutions, functionally and technically insufficient for further utilization. Thus, the motivation for the IT project implementation was mainly technically driven [8]. The technically driven motives for system/IT project implementations are also related to the lacking of an IT strategy in the case companies. In fact, a partial IT strategy, as the system/IT project was seen as a solution enabling further growth of the firm. Otherwise, the system/IT project implementations were not associated with the companies' overall business strategy plans.

\section{O. Organizational impact}

The findings revealed a difficulty in relating the system/IT project to overall business measures such as cost reduction, overall productivity improvements, increased capability, etc. (the organizational impact dimension in the [11] framework). A number of interviewees expressed limited relevance of assessing these general measures in relation to system implementation. This was explained by the dynamic environment of the case organizations. All of them are continuously growing and experience many significant changes (e.g., widening assortment, new division opening, etc.) which have more significant influence on the overall business measures than system implementation. Thus, it was perceived too complex to evaluate the effect of system because there are many other influencing factors taking part. To conclude, the dynamic environment of small and medium 
enterprises may impede evaluation of system. The researches show that the organizational transformation enhances the vigor of it by stimulating dynamic capabilities and forming a high performance system, as well as promoted the organizational capabilities, thus maintaining its sustainable competitive advantage.

\section{P. The Research Model}

Understanding the cause effect relationship between top management support and project team of system/IT project success helps organizations to control different factors and prevent their negative effect when implementing system/IT projects. The below mentioned model for these two factors relationship illustrated that some factors may be a source of consequence of other factors in system/IT project success. However having analyzed all factors it resulted that most researchers have not identified interrelationship between many of them. The researchers have taken the stand alone factors as a departure and come up with model between as it presented in the figure 1.3. It is very important for the managers to have deep understanding of the relationship that exist between several factors of system/IT project success in order to prevent the negative of these factors in system/IT project implementation stage. The proposed model which is derived from implementation risk by (Peng et al., 2009), Showing that the factors of system/IT project may be a source of consequence of other factors or the system itself. Based on the researcher observation, which result out that the relationships between many factors was not identified.

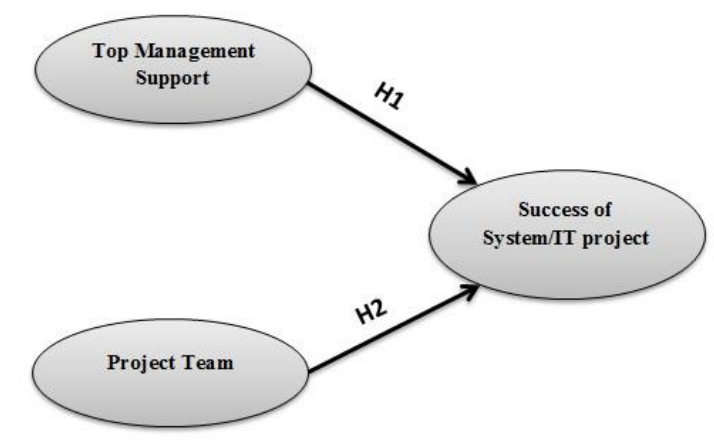

Figure 1.3 The Research Model

\section{Results}

This part present that analysis of the data gathered according to the foundation of the construction of the research model. It will also reveal the result of the project in order to evaluate the suggested research model and achieve the research objectives. This part explains about what is needed for the developed model. Hence, to prove the hypothesis of the present study, this chapter includes many sections. The first section discussion the data, second the results are highlighted. The researchers will present final results of the questionnaire. The data were analyzed through Smart Partial Least Squares (Smart PLS 2.0), using structural equation modeling (SEM) technique were selected for logical analysis.

\section{A. Measurement Model Analysis}

One of the advantageous techniques for getting measures on the internal consistency, coverage validity and discriminant validity of the research model is PLS technique. The measures are able to reveal how significantly an association between the determined constructs in the model is [18]. The notions, internal consistency, convergent validity and discriminant validity of the research model that are necessary for the suggest model. Hence, this section emphasizes on the hypotheses testing so as to the hypothesis in the study by verified. Further validation was done by measuring the research model using Smart PLS, This measurement is used to describe how individual observed constructs load on the research latent constructs. The research model offered in this investigation is examined through partial least squares (PLS). While it is structural model and measurement were evaluated through Smart PLS 2.0 [6] which is useful for evaluation of structural models parameters.

\section{B. Cronbach's alpha}

To validate the reliability of the measures indicated for the constructs, Cronbach's alpha technique was used. The purpose of performing the analysis for the reliability is to examine whether the measure consistently represent the construct that is being measured [30]. Reliability was calculated for each group of items of reflective constructs. Reliability measures the consistency among items for a given construct. Cronbach's alpha coefficient is one of the most commonly used indicators of internal consistency of a questionnaire, calculated 
using Smart PLS this technique is the average value obtained by computing the correlation every possible way. This value provides of the reliability coefficients one would obtain for all possible combinations of items. This is because the use of individual items is particularly troubling. Single item reliability are generally low, and without reliable items the validity of the items is poor at best and at worst unknown [16]. Cronbach's alpha of this research showing in table below for each construct, it was good because it is above 0.6 for all of them. In social science research, the value of 0.6 or above is considered acceptable [17]. Table 1.2 Shows that all of the constructs had enough and appropriate value expect time saving. Top management support, project team and success of system/IT project Cronbach's alpha are more than 0.6. It shows that all the constructs except time saving are reliable.

Table 1.2 Cronbach's Alpha Questionnaire Reliability Analysis

\begin{tabular}{|l|l|}
\hline & Cronbachs Alpha \\
\hline Top Management Support & 0.873316 \\
\hline Project Team & 0.895292 \\
\hline System/IT project Success & 0.817462 \\
\hline
\end{tabular}

\section{Average Variance Extracted}

The average variance extracted statistic is used to assess the convergent validity. Table below shows that all the AVE values are higher than the recommended value of 0.5 . This indicated that all the latent variables are able to explain more than half of the variance of its average indicators.

Table 1.3 AVE (Average Extracted)

\begin{tabular}{|l|l|}
\hline & AVE \\
\hline Top Management Support & 0.709866 \\
\hline Project Team & 0.584167 \\
\hline System/IT project Success & 0.515322 \\
\hline
\end{tabular}

\section{PLS Algorithm}

Partial least squares (PLS) is the name of a set of algorithms developed for use in econometrics. They have in common that no a priori assumptions are made about the model structure, a fact which has given rise to the name "soft modeling" for the PLS approach. Instead, estimates of reliability may be made using the "jackknife" or cross-validation. Figure below shows the relationship between constructs and how significance to each of other, also the relationship between constructs and indicators and how significance.

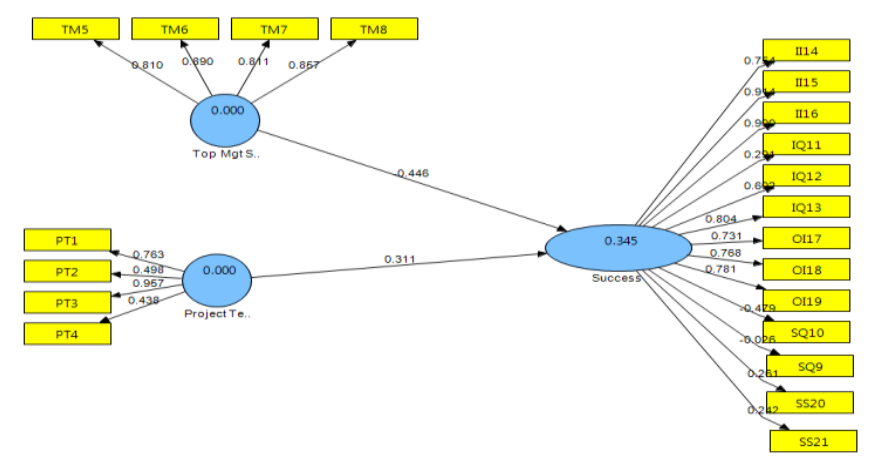

Figure 1.3 Results of Structural Model

Based on Figure 5.3, the final PLS-Graph model consists of constructs and items demonstrate. " PLS Algorithm" it is shown that almost $34 \%$ of the model can be estimated and measured with our findings. The quantity of variance in dependent variables clarified by the independent variables is shown by the (R2) value. Accordingly, by a big (R2) value, the foretelling capability of the structural model enhances. In the present investigation the (R2) value is estimated by Smart PLS algorithm, whereas for creating the t-statistics values the Smart PLS bootstrapping function is applied. The strength of relationship was significant to the success of systems. The first relationship was $(0.446)$ means there is a good relationship from top management support towards the success of systems/IT projects. Then, the second relationship was (0.311) means that a good relationship from project team towards the successful of systems/IT projects. Developer satisfaction is measured 
with two latent variables to find the satisfaction of the developers. Perhaps using more data from the respondent can help to have more estimation of our model which will be done in the main study. The paths in model for all samples of bootstrap are possible to be analyzed by PLS. The samples are gained without human intervention as a result of implementing bootstrapping. PLS technique is useful when the significant regresses are going to be analyzed [24]. In this survey, the researcher utilized bootstrapping to form 100 sub-samples. Based on the bootstrapping method which is in correspondence with inner and outer model paths, T-valued can be computed. Additionally, for the hypotheses to be tested, probability value ( $\mathrm{P}$-value) can be considered appropriate.

As shown in the figure below that the values are all less than the minimum required to examine hypothesis. The first correlation is (1.378) less than the minimum number of significant; also the second correlation is (0.782) less than the minimum number of significant. Table 1.4 and Figure 1.3 reveal the Smart PLS 2.0 results related to the $\beta$, t values, $\mathrm{p}$-values, and the $\mathrm{R} 2$.

Table 1.4 Related to $\beta$, t-values and p-values

\begin{tabular}{|l|l|l|l|}
\hline Constructs & Path Coefficients $(\beta)$ & T-values & P-values \\
\hline H1 TMS $>$ SS & 0.311173 & 1.378 & $1.79 \mathrm{E}-01$ \\
\hline H2 PPT $>$ SS & 0.446399 & 0.782 & $4.41 \mathrm{E}-01$ \\
\hline
\end{tabular}

PLS is capable to examine the paths in the model for every bootstrap sample automatically provided through the processes used in bootstrapping process. Such an approach has been utilized for analyzing the significant regresses (Austin and Tu, 2004). Bootstrapping was used in the present research to form 150 subsamples. T-values are obtained based on the bootstrapping method which coordinates with inner and outer paths. In addition, in order to examine the hypothesis, the probability value ( $\mathrm{P}$-value) is used. The researcher used $\mathrm{T}$ distribution calculations in Excel (probabilities) for examining the P-value, according to the TDIST equation:

$P($ value $)=T D I S T$ ( $t$-value, sample, 2$)$

The researchers presented the results of $\mathrm{P}$-value in the table 5.8 the $\mathrm{t}$-distribution is used in the hypothesis testing of small sample data sets. P-value $<0.05$ implies significance of the related hypothesis. As we can see the P-value for each hypothesis is calculated according to the T-value.

\section{Discussion}

The aim of this section is to provide a discussion in order to fulfill research objectives with supported by existing literature reviews. The findings shown above contribute to the relevant literature by recognizing the benefits of systems/IT projects which have been previously established. For according the study, according to the evaluation and prediction of the structural model, some data about the t-values, path coefficients $(\beta), \mathrm{P}$ values (p), squared $\mathrm{R}\left(\mathrm{R}^{2}\right)$ are identified in details.

- $\quad$ Squared $\mathrm{R}\left(\mathrm{R}^{2}\right)$ : the $\mathrm{R}^{2}$ shows the expected effect of the model of dependent variables through estimating the percentage of a construct's variance in the model [26].

- Path coefficients $(\beta)$ : A Path coefficient $(\beta)$ shows how strong and significant the associations between dependent and independent variables are [4]. It means that, a path coefficient reveals the immediate influence of variables (considered as cause) that is supposed to result in different variables (considered as effect). Since a Path coefficient can be identified based on the correlation, it is standardized while a path regression coefficient cannot be considered standardized.

- Hypothesis testing: according [20], for conducting the hypothesis testing the path significance can be determined via t-tests values by using bootstrapping procedure. Commonly, the acceptable value for t-value is large than two (t-value>2) means significant level [19].

- P-value: the P-value can be considered as a quantitative measure numerical importance of testing a hypothesis. Furthermore, regarding the studies conducted formerly, P-value $<0.05$ implies the significance of the related hypothesis (e.g., [26]).

Moreover, since $\left(\mathrm{R}^{2}\right)$ of trust equals 0.345 , it is possible to identify the alteration of the diversity of adoption through trust. That is, 0.345 of adoption might be estimated and predicted by the model. In summary, the formulated hypothesis $(\mathrm{H} 1$ and $\mathrm{H} 2)$ were supported by the data. The preceding constructs together explained 0.345 of the variance in the independent construct.

\section{From the above discussion can be concluded that:}

- Top management support has positive effect on Attitude toward developing systems/IT projects and perceived benefits. This result also is considered with previous findings [5]. Therefore, developers perceived systems/IT projects more useful have more willing to try solving all technology demands regarding to the case study of this paper.

- $\quad$ Project team has positive effect on Attitude toward developing systems/IT projects and perceived benefits. This result also is considered with previous findings [5]. Therefore, developers perceived systems/IT projects 
more useful have more willing to try solving all technology demands regarding to the case study of this paper.

- developer's attitude towards developing new systems has a positive effect on behavioural intention. This result also is consistent with previous finding [5]. Developers are interested toward developing systems/IT projects will be more significant influence on their attitude toward developing the new technology.

\section{Conclusion}

The purpose of this paper is to examine how top management support and project team can be operationalized regarding the contribution of effectiveness of system success to enhance the levels of system success. This paper aims to position the importance of top management support and project team effectiveness to achieve system success. To do so, the researchers have provided a theoretical justification and established empirically that there are substantial connects between top management support and project team effectiveness and the system success. The research model was examined using responses from 28 developers in the main department of providing systems in Universiti Teknologi Malaysia. Therefore, the researchers assume that the findings were capable of providing reasonable explanation of the top management support and project team effectiveness in system success. Thus, the results provide an even stronger support for our research hypotheses and further stabilize our research model in the future. The paper findings offer an empirical explanation that top management support and project team researchers can use to motivate and guide future studies.

\section{Acknowledgment}

I cannot express enough thanks to my supervisor for her continued support and encouragement: Dr. Nor Hidayati Zakaria. I offer my sincere appreciation for the learning opportunities provided by my university (Universiti Teknologi Malaysia).

\section{References}

[1] A. Burton-Jones, and D. W. Straub. "Reconceptualizing System Usage: An Approach and Empirical Test", Information Systems Research, 2006, (17) 3, pp. 228-246.

[2] A. R. Hevner, S. T. March, J. Park, and S. Ram, "Design science in information system research". MIS Quarterly, 2004, 28 (1), 75105 .

[3] B. Shin, "An Exploratory Investigation of System Success Factors in Data Warehousing," Journal of the Association for Information Systems, 2003, 141-170.

[4] C. Koch, "Enterprise Resource Planning: Information Technology as a Steamroller for Management Politics". Journal of Organizational Change Management, 2001, 14 (1), 64-78.

[5] C. López-Nicolás, F. J. Molina-Castello, and H. Bouwman, “An assessment of advanced mobile services acceptance: Contributions from TAM and diffusion theory models". Information \& Management, 2008, 45, 359-364.

[6] C. M. Ringle, M. Sarstedt, S. Wende, and A. Will, SmartPLS 2.0 M3. 2005, Available at http://www.smartpls.de.

[7] Calvin Chan \& Osmond Chen, "A User-Centered Approach to Student Information Systems Design", 2000.

[8] D. Chand, G. Hachey, J. Hunton, V. Owhoso, and S. Vasudevan. "A balanced scorecard based framework for assessing the strategic impacts of ERP systems". Computers in Industry,2007, 56: 558-572.

[9] E.A. Duplaga, and M. Astani, “Implementing ERP in manufacturing," Information Systems Management, 2003,20 (3), 68 -75.

[10] F. Adam, and P. O'doherty. "Lessons from enterprise resource planning implementations in Ireland-towards smaller and shorter ERP projects". Journal of information technology, 2000, 15(4), 305-316.

[11] G. G. Gable, and D. Sedera, "Knowledge management competence for enterprise system success". The Journal of Strategic Information Systems, 2010, 19(4), 296-306.

[12] G. Gable, D. Sedera, and T. Chan, "Re-conceptualizing Information System Success:the IS-Impact Measurement Model" Journal of the Association for Information Systems, 2008, 9(7). 377-408.

[13] G. J. Norris, K. Hurley, M. Hartley, J. R. Dunleavy and J. D. Balls, "E-Business and ERP Transforming the Enterprise", 2000.

[14] H. H. Chen, S. C. Chen, and L. H. Tsai. "A study of successful ERP-from the organization fit perspective". Journal of Systemics, Cybernetics and Informatics, 2009, 7(4), 8-16.

[15] I. Benbasat, and R. W. Zmud. "The Identity Crisis Within The IS Discipline: Defining And Communicating The Discipline's Core Properties", MIS Quarterly. 2003, (27)2, 183-194.

[16] J. Gliem, and R. Gliem, "Calculating, interpreting, and reporting Cronbach's Alpha Reliability Coefficient for Likert-type scales". Journal of Organizational and End User Computing, 2003, (24:2) 33-53.

[17] J. P. Robinson, P. R. Shaver, and L. S. Wrightsman, "Criteria for scale selection and evaluation". Measures of Personality and Social Psychological Attitudes. 1990, 1-16.

[18] J. R. Edwards, R. P. Bagozzi, "Multidimensional Constructs in Organizational Behavior Research" Journal of Organizational and End User Computing, 2001, 4 (2), 144-192.

[19] J. W. Eckblad, "How many samples should be taken?" BioScience. 1991, 41: 346-348.

[20] J.N. Reddy and C.D. Chin. Thermomecanical analysis of functionally graded cilinders and plates. Journal of Thermal Stresses, 21:593-626, 1998.

[21] M. Bradford, and J. Florin. "Examining the role of innovation diffusion factors on the implementation success of enterprise resource planning systems", International Journal of Accounting Information Systems, 2003, 205 - 225.

[22] M. L. Markus, S. Axline, D. Petrie, and C. Tanis, "Learning from Adopters' Experiences with ERP-Successes and Problems", Journal of Information Technology, 2000, 15, PP. 245-265.

[23] N. P. Melone, "A Theoretical Assessment Of The User-Satisfaction Construct," Management Science, 1990, (36)1. 76-91.

[24] P. Austin, and J. V. Tu. "Temporal changes in the outcomes of acute myocardial infarction in Ontario". Journal of Personality and Social Psychology. 2004, 16(1)1257-61. 
[25] P. Bingi, M.K. Sharma, and J.K. Godla. "Critical Issues Affecting an ERP Implementation. Information Systems Management", 1999, 7-14.

[26] P. Ifinedo, "An empirical analysis of factors influencing Internet/e-business technologies adoption by SMEs in Canada". International Journal of Information Technology \& Decision Making, 2011, 10(4), 731-766.

[27] R. Ayyagari, V. Grover, and R. Purvis. "Technostress: Technological Antecedents and Implications". Management Information Systems Quarterly. 2011, 35(4), 831-858.

[28] R. C. MacCallum, and M. W. Browne, "The use of causal indicators in covariance structure models: Some practical issues". 1993 , 533-541.

[29] R. Sabherwal, A. Jeyaraj, and C. Chowa, "Information System Success: Individual and Organizational Determinants. Management Science, 2006, 52 (12), 1849-1864.

[30] S. B. Green, and N. J. Salkind, "Using SPSS for Windows and Macintosh: Analyzing and understanding data". Upper Saddle River, 2005.

[31] S. D. Petter, and A. Rai, "Specifying Formative Constructs in Information systems research," MIS Quarterly, 2007, (31)4 623-656.

[32] S. Shang, and P.B. Seddon, "Assessing and Managing the Benefits of Enterprise Systems: the Business Manager's Perspective". Information Systems Journal, 2002, pp 271-299.

[33] S.M. Jafari, M.R. Osman, R.M. Yusuff, and S.H. Tang, "ERP Systems Implementation in Malaysia: The Importance of Critical Success Factors". International Journal of Engineering and Technology, 2006, 3(1), 125-131.

[34] V.A. Mabert, A. Soni, and M. Venkataramanan, "The impact of organization size on enterprise resource planning (ERP) implementations in the US manufacturing sector", Omega-International Journal of Management Science, 2003, 31 (3), 235-246.

[35] W. H. DeLone, and E. R. McLean. "Information systems success revisited. In Proceedings of the 35th Hawaii international" conference on system sciences, 2002, 7-10.

[36] W. H. DeLone, and E. R. McLean. "Information systems success: The quest for the dependent variable". Information Systems Research, 1992, 3(1), 60-95.

[37] W. H. DeLone, and E. R. McLean. "The Delone and Mclean model of information systems success: A ten-year update". Journal of Management Information Systems, 2003, 19(4), 9-30.

[38] W. T. Lin, and B. B. M. Shao, "Relative Sizes of Information Technology Investments and Productive Efficiency: Their Linkage and Empirical Evidence," Journal of the Association for Information Systems, 2000.

[39] Z. Huang, "A compilation research of ERP implementation critical success factors". Journal of Issues in Information Systems, 2010, 11(1), 507-512. 